\title{
Acidente humano por picadas de abelhas africanizadas
}

\author{
Human accident for stings of Africanized bee
}

\author{
Flávia Aparecida de Oliveira ${ }^{1}$, Janaína Valadares Guimarães ${ }^{2}$, Marlene Antônia dos Reis ${ }^{1}$ \\ e Vicente de Paula Antunes Teixeira ${ }^{1}$
}

\begin{abstract}
Resumo São relatados cinco casos de pessoas picadas por abelhas africanizadas (AA). Quatro foram vítimas de múltiplas picadas variando de 25 a 60, que apresentaram cefaléia intensa, náuseas e vômitos, relacionados aos efeitos tóxicos do veneno, mas evoluíram bem. $O$ outro caso foi vítima de uma única picada de $A A$ e evoluiu para o óbito, por provável anafilaxia.
\end{abstract}

Palavras-chaves: Abelha africanizada. Acidente humano. Anafilaxia. Múltiplas picadas. Veneno de abelha.

Abstract It is report five cases of stings of africanized bees (AB). Four of them were vitims of multiple stings, varying from 25 to 60, that presented severe headache, nauseas and vomits, related to the clinic effect of the toxicity of the venom, with good evolution. The other case was victim of a single sting of $A B$ and died after probable anaphylaxis.

Key-words: Africanized bee. Human accident. Anaphylaxis. Multiple stings. Bee venom.

As abelhas africanizadas (AA) surgiram no Brasil na década de cinqüenta, resultante da hibridização das abelhas africanas, trazidas da África, com as européias já existentes na natureza brasileira naquela época. As AA se caracterizam por serem muito agressivas e atacar as suas vítimas em enxames, inoculando grande quantidade de veneno ${ }^{15}$. Há estudos sobre acidentes por múltiplas picadas de abelhas no Brasil $^{611}$; no entanto, a divulgação científica dos casos com menos de cem picadas não fatais tem sido pouco freqüente ${ }^{3}$. Assim, o objetivo do trabalho foi relatar cinco casos de vítimas com menos de cem picadas de AA, sendo que um deles evoluiu para o óbito.

\section{RELATO DOS CASOS}

Caso 1 - 53 anos, masculino, foi vítima de 25 picadas de abelhas, aproximadamente. Apresentou cefaléia intensa tipo queimação, náuseas, vômitos intensos, sudorese e tontura. Cerca de 5 horas após o acidente, tensão arterial $180 \times 80 \mathrm{mmHg}$, recebendo medicação sintomática. Evolução: no dia seguinte, sentiu dormência na cabeça com edema palpebral moderado.
Caso 2 - 28 anos, masculino, foi vítima de cinqüenta picadas de abelhas, aproximadamente. Apresentou cefaléia intensa tipo queimação, náuseas, vômitos intensos, astenia, dor muscular e nas articulações dos tornozelos, tremores intensos, tensão arterial $90 \times 70 \mathrm{mmHg}$ e pulso 80 batimentos/ minuto. Evolução: reação inflamatória nos locais das picadas nas mãos durante quinze dias.

\footnotetext{
1. Disciplina de Patologia Geral da Faculdade de Medicina do Triângulo Mineiro (FMTM); 2. Disciplina de Anatomia da Universidade de Uberaba (UNIUBE), Uberaba, MG.

Apoio financeiro: Fundação de Ensino e Pesquisa de Uberaba (FUNEPU), Fundação de Amparo à Pesquisa do Estado de Minas Gerais (FAPEMIG) e Conselho Nacional de Desenvolvimento Científico e Tecnológico (CNPq).

Endereço para correspondência: Profa . Marlene Antônia dos Reis. Disciplina de Patologia Geral, Faculdade de Medicina do Triângulo Mineiro. Rua Frei Paulino 30, 38025-180, Uberaba, MG.

e-mail:mareis@mednet.com.br.

Recebido para publicação em 7/2/2000.
} 
Caso 3 - 24 anos, masculino, foi vítima de cinqüenta picadas de abelhas, aproximadamente. Apresentou cefaléia intensa tipo queimação, náuseas, vômitos intensos, tontura, tensão arterial $110 \times 70 \mathrm{mmHg}$ e pulso 80 batimentos/minuto.

Caso 4 - 20 anos, feminino, foi vítima de sessenta picadas de abelhas, aproximadamente. Apresentou cefaléia intensa tipo queimação, náuseas, vômitos intensos, dormência nas mãos, tremores intensos, astenia e por cerca de 4 horas confusão mental e agitação psico-motora; tensão arterial $120 \times 70 \mathrm{mmHg}$ e pulso 90 batimentos/ minuto. Evolução: nos 6 dias subseqüentes, apresentou aumento da temperatura, eritema e prurido moderado no local das picadas e reação urticariforme nos membros inferiores. Além disso, rouquidão que durou 12 dias.

Caso 5 - 46 anos, feminino. A paciente foi encaminhada ao pronto socorro do Hospital Escola da Faculdade de Medicina do Triângulo Mineiro, Uberaba-MG, com história de ter sido picada por uma abelha africanizada há 2 horas. Ao exame físico não havia sinais vitais. Há seis meses, a vítima apresentou perda dos sentidos após duas picadas de abelhas quando foi orientada a usar uma injeção (não relatado o nome), caso fosse novamente picada. Há cerca de vinte anos, vinha apresentando quadro de edema nos membros inferiores e aumento da tensão arterial.

Diagnóstico anatomopatológico. Provável choque anafilático caracterizado por edema, congestão e focos de hemorragia sistêmicos, destacando as vias aéreas superiores e o intenso edema das partes moles da região cervical. Petéquias e sufusões hemorrágicas pleurais acompanhadas de edema e hemorragia pulmonar com focos de colapso. Congestão e edema encefálicos moderados difusamente, acompanhados de focos de hemorragia subaracnóide e perivascular no parênquima. Congestão acentuada no baço, na mucosa do trato digestivo, nas supra-renais e no rim. Cardiopatias hipertensiva e isquêmica com moderadas placas de aterosclerose na coronária descendente anterior. Hiperplasia do anel linfático oral incluindo as tonsilas palatinas bilateralmente. Obesidade com índice de massa corporal $=33,24 \mathrm{~kg} / \mathrm{m}^{2}$.

Condutas nos casos 1 a 4 . Observação clínica por 14horas, aproximadamente. Dieta zero, soro fisiológico a $0,9 \%$, Fenergan, Flebocortid, Dipirona e aquecimento. No caso 4 foi acrescido Diazepan.

\section{DISCUSSÃO}

Os quatro casos de múltiplas picadas de $A A$ tiveram boa evolução e provavelmente, as alterações encontradas foram decorrentes da toxicidade do veneno das AA. Os sintomas comuns a eles foram cefaléia, náuseas e vômitos. A cefaléia foi pouco encontrada em outros estudos ${ }^{2}$, náuseas e vômitos também foram encontrados em outros trabalhos ${ }^{239}$. Após o envenenamento, a liberação de histamina endógena estimula o aumento de secreção gástrica que pode contribuir com o desencadeamento das náuseas e vômitos ${ }^{4}$.

A hipotensão observada no caso 2 foi também descrita por outros autores ${ }^{2}$. Ela pode ser explicada pelo efeito vasoativo (vasodilatação e aumento da permeabilidade vascular), da histamina, leucotrienos e outros mediadores químicos. Estes mediadores são liberados endogenamente pela ação da histamina, do peptídeo degranulador de mastócitos, da melitina (que representa $50 \%$ do peso seco do veneno) e da fosfolipase $A_{2}$ que compõem o veneno ${ }^{12}$. Experimentalmente, já foi relatado hipotensão logo após a inoculação do veneno da $A^{7}$.
Agitação e confusão mental encontradas no caso 4 foram também descritas em vítimas de uma a múltiplas picadas ${ }^{2611}$. A apamina, constituinte do veneno, tem atuação na junção neuromuscular em camundongos, resultando em hiperexcitabilidade e convulsão ${ }^{8}$. A melitina pode apresentar ação inibidora da anticolinesterase ocasionando excitação sináptica ${ }^{11}$. Logo, a ação destas substâncias podem levar a agitação e confusão mental. Além disso, a rouquidão apresentada por esta paciente, pode ser associada a um possível edema de laringe provocado pelos constituintes do veneno da $\mathrm{AA}^{4}$.

O caso 5 de uma picada pode ser classificado como acidente por hipersensibilidade aos constituintes do veneno de $A A$, devido a história anterior de sensibilidade ao veneno, a independência da quantidade de picadas e aos achados anátomo-patológicos ${ }^{111}$. Estes são os acidentes fatais mais freqüentes por picadas de $A A^{112}$. O edema de vias aéreas, incluindo a região da laringe, congestão, edema e hemorragia em diferentes órgãos foram também descritos por outros autores $^{9}$. O edema de laringe, geralmente 
presente na anafilaxia, pode ser um dos eventos determinantes do óbito da vítima ${ }^{12}$. Além disso, a obesidade pode ter contribuído para a dificuldade respiratória do caso 5 . Dentre os efeitos tóxicos do veneno destacam-se a ação vasoativa da histamina e dos leucotrienos que liberados endogenamente, podem contribuir para o estabelecimento do edema e da congestão encontrados em vários órgãos ${ }^{48}$. Estes achados foram descritos também em acidentes por múltiplas picadas ${ }^{611}$, mostrando a possibilidade de sobreposição dos efeitos tóxicos com a hipersensibilidade.

As cardiopatias hipertensiva e isquêmica apresentadas pela paciente de 46 anos (caso 5) podem diminuir a capacidade de adaptação aos efeitos da anafilaxia. Segundo alguns autores, a idade acima de 40 anos e outros fatores préexistentes, como as doenças cardiovasculares, destacando-se a arteriosclerose na coronária, podem contribuir para o efeito letal da reação anafilática ${ }^{12}$.

Nos casos com mais de 50 picadas de abelhas é recomendável que as vítimas fiquem em observação por 24 horas independente da sintomalogia, devido ao risco de desenvolvimento de sinais e sintomas tardios que necessitem de assistência imediata ${ }^{10}$. Seria conveniente que os acidentes por picadas de abelhas fossem notificados, pois proporcionaria mais conhecimentos sobre a cronologia e a variedade das manifestações clínicas destes envenenamentos.

\section{REFERÊNCIAS BIBLIOGRÁFICAS}

1. Barraviera B. Acidentes por abelhas e vespas. In: Barraviera B (ed) Venenos - Aspectos clínicos e terapêuticos dos acidentes por animais peçonhentos. EPUB, Rio de Janeiro, p. 339-344, 1999.

2. Coelho LK, Rodrigues NC, Hermes EM, Silva LM, Kowalki ME. Resultados preliminares de um estudo envolvendo pacientes com picadas de abelhas. In: Resumos da $\mathrm{V}$ Reunião Anual da Federação de Sociedades de Biologia Experimental - FESBE, Caxambu, p. 400, 1990.

3. Conde JE. Quando a ficção vira realidade. Ciência Hoje 18:70-73, 1995.

4. Cotran RS, Kumar V, Robbins SL, Schoen FJ. Doenças da imunidade. In: Cotran RS, Kumar V, Robbins SL, Schoen FJ (eds) Robbins Patologia Estrutural e Funcional, $5^{\text {a }}$ edição, Guanabara Koogan, Rio de Janeiro, p. 152-212, 1996.

5. Diniz Filho JAF, Malaspina O. Abelhas africanizadas nos anos 90. A história mostra que a população aprendeu a conviver com essas abelhas. Ciência Hoje 90: 73-76, 1995.

6. França FOS, Benvenuti LA, Fan HW, Santos DR, Hain SH, Picchi-Martins FR, Cardoso JLC, Kamiguti AS, Theakston RDG, Warrell DA. Severe and fatal mass attacks by "killer" bees (Africanized honey bees Apis mellifera scutellata) in Brazil: clinicopathological studies with measurement of serum venom concentrations. Quarterly Journal of Medicine 87: 269-282, 1994.

7. Guimarães JV, Machado BA, Reis MA, Busollo AC, Sena GA, Costa RS. Avaliação da pressão arterial no empeçonhamento experimental por abelhas africanizadas. In: Resumos da XXII Reunião Anual da Federação de Sociedades de Biologia Experimental FESBE, Caxambu p. 376, 1997.

8. Habermann E. Bee and wasp venoms. The biochemistry and pharmacology of their peptides and enzymes are reviewed. Science 177:314-322, 1972.

9. Harvey P, Sperber S, Kette F, Heddle RJ, RobertsThomson PJ. Bee - sting mortality in Australia. The Medical Journal of Australia 140:209-211, 1984.

10. Kolecki P. Delayed toxic reaction following massive bee envenomation. Annals of Emergency Medicine 33:114116, 1999.

11. Mendes RP, Meira DA, Molinari H, Rodrigues PS, Coelho KYR. Acidentes por múltiplas picadas de abelha. Arquivo Brasileiro de Medicina 64:81-88, 1990.

12. Vetter RS, Visscher PK, Camazine S. Mass envenomations by honey bees and wasps. West Journal Medicine 170:223-227, 1999. 